\title{
EL CONCEPTO DE RESPONSABILIDAD SOCIAL DEL ESCRITOR EN MIGUEL DE UNAMUNO (1)
}

\author{
Guillermo Carnero \\ Universidad de Alicante
}

Unamuno es un escritor de lectura difícil y de asentimiento más difícil todavia, y ello por dos razones fundamentales, al margen del contenido doctrinal mismo de su pensamiento. En primer lugar, y no por tópico es menos cierto, su carácter movedizo y contradictorio puede ser desorientador para quienes se sientan incómodos oscilando a su compás. El propio Unamuno se sabla y se admitía contradictorio, y consideraba además que el serlo era un síntoma de vitalidad $\mathrm{y}$ juventud mental, de sinceridad y de autenticidad. Eso viene a decir en el discurso con que agradeció el nombramiento de Ciudadano de Honor de la República en 1935 (2) al referirse a la fecunda concordancia de discordancias que a su modo de ver lo caracterizaba como español genuino; aunque parezca

(1) Este ensayo tuvo un origen completamente viviparo; nacio de la lectura y relectura de textos unamunianos para placer personal y solitario. Conservó ese carácter al convertirse en conferencia en julio de 1982, y creo que aśl lieg6 más directamente al auditorio. Se publica ahora con mínimas concesiones al oviparismo académico.

(2) Obras Completas, ed. Escelicer, IX, pp. 458-461. Se citará siempre esta edición. 
poco afortunado el llamar fecundas a las discordancias españolas a un año de la «guerra civil incivil» de 1936.

En segundo lugar, el pensamiento de Unamuno es un pensamiento en marcha, que se va haciendo a lo largo del tiempo y que en sus sucesivos estados ha quedado impreso, en lugar de ofrecernos unos resultados finales con ocultación de su proceso genético. Con lo cual, además de ser en ocasiones contradictorio, como ya he dicho, es también a menudo fragmentario: quiero decir que podemos encontrarnos en la necesidad de reconstruir un supuesto proceso lógico por el procedimiento de ir ensamblando textos separados por un notable lapso de tiempo, con todos los riesgos que ello supone (3). Pero es inevitable actuar así cuando la materia del tema que nos ocupa se halla dispersa en gran cantidad de artículos, discursos y obra en volumen, y no sistematizada en un tratado único.

Posiblemente a Unamuno no le gustaría lo que hay que hacer con esos escritos suyos para entenderlos. En su Diario nos dice que la inquietud religiosa lo llevaba a leer obras doctrinales y devotas, con deseo de recibir consuelo e iluminación, pero enseguida ese deseo era.sustituido por la deformación profesional del profesor que llevaba dentro, $y$ olvidando o postergando el problema íntimo, se dedicaba a tomar notas de investigador (4). Que su sombra nos perdone si nos acercamos a su pensamiento con voluntad de formar, sobre la dispersión, un modelo articulado; ordenar es también una pasión.

No se me oculta que hay quien piensa que el nombre de D. Miguel, en materia de compromiso político, huele a cuerno quemado. La resistencia democrática de nuestra posguerra magnificó antes a Machado que a

(3) Me refiero especialmente a la llamada crisis de 1897 y sus consecuencias ideológicas. La consideración conjunta o sucesiva de textos anteriores y posteriores a esa crisis no supone ignorancia o desprecio de las consecuencias de dicha ruptura, y si el deseo de documentar el origen y antigüedad en Unamuno de una problemática que interesa aquí en la solución personal del autor, al que no se "valora» en modo alguno por su fidelidad a ideologias determinadas. Ver: Basdekis, D. «El populismo del primer Unamuno», en W.AA. La crisis fin de siglo..., Barcelona, Ariel, 1975; Blanco Aguinaga, C. "El socialismo de Unamuno", en Juventud del 98, Madrid, Siglo XXI, 1970; Díaz, E. Revisión de Unamuno, Madrid, Tecnos, 1968; Pérez de la Dehesa, R. Polfica y sociedad en el primer Unamuno, Madrid, Ciencia Nueva, 1966 y Barcelona, Ariel, 1973; Pizán, M. El joven Unamuno, Madrid, Ayuso, 1970: y los estudios preliminares en: Diaz, E. (ed.) Unamuno: pensamiento polltico, Madrid, Tecnos, 1965, y Ribas, P. (ed.). Miguel de Unamuno. Escritos socialistos... 1894 1922, Madrid, Ayuso, 1976.

(4) Ed. cit., VIII, p. 818. 
Unamuno, y aquí topamos otra vez con las famosas contradicciones que, en el terreno político estricto, hicieron que Unamuno, como era de rigor, no encajara en los altares de nadie o de casi nadie. Tuvo una primera etapa de socialismo marxista sui generis, que abandonó a fin de siglo a causa de una crisis espiritualista. Su actividad política sostenida lo llevó, tras diversos avatares, a ser desterrado por Primo de Rivera, $y$ se vengó escribiendo poemas injuriosos contra él y Alfonso XIII. Criticó abiertamente la realidad republicana, y en los últimos años de su vida logró, por voluntad y nor destino, indisponerse con las dos Españas; algunas de sus obras fueron incluidas en el Indice de Libros Prohibidos. En junio 1920 (Nuevo Mundo) publica un artículo, «De la democracia bolchevista» (5) donde afirma que "el más desenfrenado imperialismo será el de un estado comunista», poniéndose enfrente de la gran esperanza rusa que iba a acariciar la intelectualidad progresista europea de su tiempo. Su Discurso sobre la lengua española en las Cortes de septiembre 1931 (6) está llamado a irritar a todos los autonomistas que haya bajo la capa del cielo, especialmente si son vascos. $Y$ dos artículos de 1933, "Ceros a la derecha o a la izquierda» (Ahora) (7) y «Eso no es revolución») (Heraldo de Aragón) (8) nos llevan del paradojismo y la boutade al escepticismo político más absoluto. Para mayor inri, en el Diario leemos que el verdadero comunismo es el de la comunión sacramental, que nos hace participar a todos de Dios (9). Pero el desencanto político de Unamuno no debe hacernos olvidar dos cosas. Primera, que fue siempre un hombre dispuesto a dar la cara, hasta muy extremas consecuencias, frente a la maquinaria del poder constituido, y lo prueban las represalias que hubo que sufrir. Asi lo consideró y admiró la España de su tiempo: no hay más que hojear el número homenaje que le dedicó $L a$ Gaceta Literaria en 1930. Segunda, que el concepto unamuniano de compromiso tuvo una influencia avasalladora: sus ideas al respecto son generalmente admitidas en los ambientes literarios españoles hasta que el estado de cosas que hubo de conducir a la Guerra Civil exija planteamientos de mayor radicalidad y de estricta militancia.

Por lo que se sabe, la generación del 98 fue la introductora en el vocabulario usual del concepto de «intelectual», que vino a sustituir, con matizaciones esenciales de significado político, al más impreciso de

(5) Ibid, V, pp. 1139-1141.

(6) Ibid, III, pp. 1350-1361.

(7) Ibid, V, pp. 1192-1194.

(8) Ibid, VII, pp. 812-814.

(9) Ibid, VIII, p. 782. 
«escritor (10). Un escritor es el miembro de una categoría profesional que se dedica a la creación literaria. Un intelectual, además de un escritor, puede ser un científico en cualquier materia, por supuesto no necesariamente filológica, o un miembro de las profesiones liberales; pero, además, en el concepto mismo de uintelectual» está implícita una relación entre individuo pensante o creador, y sociedad, que presupone en el primero interés y actividad frente a las cuestiones públicas. El intelectual se siente miembro de un grupo internamente solidario $y$ activo frente a la organización social, en la que desempeña un papel de fermento o de conciencia permanente, además de sentirse obligado a asumir, cuando sea necesario, conductas más decisivas.

Corresponde determinar cuál es la índole y los límites de la función del intelectual así definido. Se ha dicho que el intelectual es el escritor, científico o profesional en la medida en que se considere investido de una función social. Ello presupone:

$1^{\circ}$. Que por ser los llamados intelectuales un grupo social fuertemente diferenciado, su función tendrá que ser consecuentemente muy especifica.

$2^{\circ}$. Que, si el intelectual es un ser cualitativamente diferenciado y socialmente proyectado, tendrá que seguir siendo lo primero antes de, durante y después de dicha proyecicón. Parece una perogrullada pero no lo es. Quiero decir que la persona carente de los conocimientos y capacidades esenciales al concepto de intelectual no podrá nunca serlo, por mucho que se proyecte; y también que el intelectual dejará de serlo si en tal proyección se desnaturaliza o pierde su ser específico.

$3^{\circ}$. Que, si el escritor - limitémonos desde ahora a él - tiene, aun antes de considerarse intelectual, planteado un problema de comunicación con el público, ese problema se agrava cuando se trata de cumplir una función social. La incomunicación entre escritor y público puede suponer descenso o carencia de ventas, pero nadie deja de ser escritor por no vender sus libros, o no hacerlo en determinada cantidad. En cambio, no se concibe un intelectual sin un mínimo contacto con el cuerpo social.

Traduciendo todo esto a un lenguaje práctico, resulta lo siguiente:

(10) Ver: Inman Fox, E. «El año de 1898 y el origen de los intelectuales», y Marichal, J. "La generación de los intelectuales y la política», en La crisis de fin de siglo... cit. 
$1^{\circ}$. Si la función social del intelectual es específica, éste se halla frente al riesgo de dejar de serlo a fuerza de querer serlo. Es decir, que hay un posible vicio por exceso del intelectual, cuando se emplea en cumplir su función social olvidando que es, fundamentalmente, un escritor, y se convierte en mero hombre político.

$2^{\circ}$. Al intelectual le acecha otro vicio contrario, un vicio por defecto. Consiste en que, a fuerza de enfatizar su naturaleza de escritor, cultivándola por derroteros minoritarios o peregrinos, se ocupe de cuestiones que socialmente no tienen eco, o se exprese en un lenguaje inaccesible a la mayoría.

$3^{\circ}$. Deberá haber, entre ambos vicios, una actitud intermedia correcta, entre el elitismo y el olvido de la exigencia creativa. En ella habrá de residir el verdadero papel del intelectual.

Veamos ahora cómo en la obra de Unamuno se plantean las anteriores cuestiones, deducidas en abstracto del concepto de «intelectual». Selecciono textos que me parecen significativos, sin la pretensión de elaborar un catálogo exhaustivo o unas concordancias temáticas.

EL VICIO POR EXCESO DEL INTELECTUAL. Lo encontramos formulado, por ejemplo, en los "Diálogos del escritor y el político" (11) que aparecieron en Los Lunes de El Imparcial en noviembre $y$ diciembre 1908. El Político empieza afirmando que el Intelectual habla pero no actúa; y el Escritor argumenta que hace algo más importante, y previo a toda acción, crear conciencia. colectiva con sus escritos: «El fin del escritor es escribir e influir con sus escritos en los demás». Y si se convirtiera en político profesional, perdería en la acción el tiempo para la reflexión y la independencia de criterio, al estar sujeto a consignas de partido. Lo mismo en «Hacer política» (Nuevo Mundo, 1915) (12); aquí Unamuno sostiene que su misión es «hacer opinión pública, fraguar conciencia colectiva, y no hacer elecciones». Y más adelante dice:

Debemos contribuir a hacer la opinión pública, no para que ésta nos llame luego a representarla. Porque no son los forjadores de conciencia pública los que mejor la pueden representar después de forjada. Su obligáción es no detenerse nunca, y el que

(11) Ibid., V, pp. 962-975.

(12) lbid., V, pp. 1064-1066. 
acepta la representación de un momento de conciencia, se detiene.

En "Maquiavelo o de la política» (El Día, 1917) (13) afirma Unamuno que la obra de un escritor es tan de utilidad pública como las actividades legislativas o ejecutivas. En "La representación política del escritor" (EI Liberal, 1920) (14) se niega a admitir que la labor del intelectual no inscrito en un partido político sea ineficaz, diciendo que entre escritor y público se establece una relación tan eficaz como la que cohesiona un partido. $Y$ éstos tienen la desventaja de suponer «bandera y grito, matrícula y cuota, comités y jefes, $y$ listines de matrículan; y lo que es peor, una ortodoxia dogmática cuya aceptación domestica e inutiliza al intelectual, que es para Unamuno la conciencia, siempre despierta y crítica, de la sociedad. En su citado discurso de 1935 insistirá una vez más en los riesgos de ser hombre de partido.

Me he referido al vicio por exceso del intelectual, que consiste en hacerse hombre político profesional. En el último decenio de su vida detecta Unamuno otro posible vicio en el mismo sentido, que preocupó profundamente a los intelectuales comprometidos de los años treinta. Me refiero a los dogmas del "Realismo socialista» y el "Arte proletario», dogmas emanados de la ortodoxia comunista del momento y responsables de la bancarrota del movimiento Superrealista desde el Congreso de Jarkov de 1930. Estos dogmas suponen en síntesis: que la lucha de clases ha de ser, en sus múltiples variedades, el tema obligado del arte; que la expresión artística ha de simplificarse todo lo necesario para que ese arte cumpla una función primordial de propaganda; y que los artistas han de someterse en su trabajo a las directrices y censura del Partido.

No tuvo Unamuno que esperar a que el stalinismo lo pusiera sobre aviso de los riesgos que el arte de propaganda supone, tanto para el arte como para la credibilidad y eficacia subsiguiente de la propaganda misma. En La Lucha de Clases, diciembre 1895, comenta el estreno del drama social Juan José, de Joaquín Dicenta (15), y se pregunta si tiene «tesis socialista», para contestarse que si la obra es válida no es por su tesis, sino por la habilidad dramática con que está revestida de personajes y situaciones:

(13) Ibid., IV, pp. 1109-1112.

(14) Ibid., VII, pp. 801-802.

(15) lbid., IX, pp. 550-551. 
El drama del Sr. Dicenta es bueno artísticamente por revelar la esencia de la vida social de hoy en uno de sus aspectos, por ser resplandor de la verdad, por revelarnos la honda significación de un mundo. No es bueno por tener tesis socialista, sino que tiene tesis socialista porque es bueno.

En «La labor patriótica de Zuloaga» (Hermes, Bilbao, 1917) (16), «¿Existe una literatura proletaria?» (Amauta, Lima, 1928) (17), y "Hablemos de teatro» (Ahora, 1934) (18), va Unamuno perfilando su pensamiento al respecto. Se niega a admitir que los problemas económicos y sociales sean los únicos que hayan de interesar al hombre, que deba existir un arte específicamente de clase, y que pueda definirse a un hombre por la clase a la que pertenece. Considera que la idea de fabricar un arte específicamente destinado al proletario es populismo burgués basado en el desprecio hacia una clase obrera a la que se cree incapaz de sentimientos artísticos, la cual no necesita que se le predique, como si se tratara de un hato de deficientes mentales, una moraleja política que, por instinto al menos, conoce sin duda mejor que el predicador. Para Unamuno, es arte "abogadesco» o «jesuítico» el que se sustenta en fines pragmáticos de propaganda, $y$, por proponérselos de modo apriorístico y racionalista, no puede lograr eficacia artística ni, por lo tanto, impacto ideológico.

EL VICIO POR DEFECTO DEL INTELECTUAL. Consiste en que éste se olvide de lo que es $\dot{y}$ se convierta en un escritor "artificioso». "Artificioso» es, en el pensamiento de Unamuno, concepto antitético de upopular»; enseguida veremos qué entiende Unamuno por escritor popular, al margen del significado más banal o usual de este concepto.

Lo artificioso, para Unamuno, se da en el escritor que se niega a cumplir la función social que le es propia en tanto que intelectual, y adopta una actitud elitista, de absurda superioridad, sin darse cuenta de que el escritor popular tiene su propia superioridad, correcta y útil, en cuanto posee mayor conciencia y capacidad expresiva que el resto de sus semejantes. El artificioso pretende basar su superioridad en la exhibición de una supuesta naturaleza (ideas, emociones) refinada e inusual; se caracteriza por el cerebralismo y el desarraigo, la incapacidad para asumir los problemas trascendentes, que para Unamuno son los

(16) Ibid., VII, pp. 765-768.

(17) Ibid., IX, pp. 1207-1209.

(18) Ibid., VII, pp. 718-720. 
propios de la condición humana (tanto individuales e íntimos como colectivos) y por la consiguiente exaltación de las preocupaciones de técnica expresiva como valor y meta máximos. Recomienda en cambio Unamuno desconfiar del esteticismo, del perfeccionismo y de toda forma de arte que ponga su empeño en logros técnicos o formales. A primera vista se observa la coincidencia de estas ideas unamunianas con las que acuñará Ortega con el nombre de «deshumanización del arte».

Las encontramos ya en un escrito juvenil de Unamuno, de su etapa de socialismo militante: me refiero al artículo "Función social del arte» (La Lucha de Clases, diciembre 1896) (19). El arte, se dice en él, no puede reducirse a diversión o pasatiempo; debe afectar, por la vía de los sentimientos, a quienes no son capaces de acceder al nivel de las ideas. Unamuno anda en esa fecha a vueltas con el marxismo, y pone el acento en la educación política de las masas por medio del arte:

Si la luz ha de iluminar las honduras mas tenebrosas de la cuestión social, caliente el arte la fría indiferencia respecto a tal cuestión.

En «Literatismo» (La Revista Blanca, julio 1898) (20), opina que «la fórmula del Arte por el Arte suele ocultar la concepción más antisocial del Arte», es "una profunda inmoralidad» y «la gangrena del intelectualismo». El antídoto estará en popularizar la expresión artística y buscar inspiración en la realidad, no en la literatura.

El Correo de Valencia inserta en agosto 1900 el artículo "Turrieburnismo» (21), que vuelve a atacar el virtuosismo literario y a definir el esteticismo como resultado del desinterés por lo «hondamente humano». Y al prologar en La Nueva Era su discurso en los Juegos Florales bilbaínos de 1901 (22) se expresa Unamuno con mayor claridad:

La literatura no puede ser en parte alguna, y menos que en otra parte en España, labor de mera contemplación artística. El encerrarse el literato en su torre de marfil a rezar letanías a la Belleza es hoy un crimen. Nuestro primer deber es el de educar al pueblo.

(19) Ibid., IX, pp. 688-689.

(20) Ibid., IX, pp. 759-763.

(21) Ibid., VII, pp. 1272-1273.

(22) Ibid., IX, pp. 819-821. 
Recordemos también el ensayo "El sepulcro de Don Quijote» (La España Moderna 1906) (23). Unamuno desdeñará siempre la literatura artificiosa, aun cuando se haya despegado de las implicaciones al respecto propias de su marxismo inicial.

Las grandes corrientes literarias de su tiempo le parecieron a Unamuno viciadas de artificiosidad, y dirigió sus burlas y censuras contra el Modernismo, Vanguardismo y Gongorismo. En «La Balada de la prisión de Reading" (Las Noticias, Barcelona, octubre 1897) (24)dice:

Aquí también, en España [...] hay sus Oscar Wilde, muy rebajados en verdad, con menos audacia. Afectan vivir en la torre ebúrnea de sus exquisiteces y refinamientos [...]. No parece interesarles nada hondamente humano. El arte se convierte en sus manos en un bibelote indigno, en un juego estéril [...]. El esteticismo empieza a corroer nuestras letras; difúndese por ellas un soplo de erotismo blandengue y baboso, de mozos impúberes o de viejos decrépitos.

Contesta en la revista Helios de julio 1903 a una encuesta sobre Góngora (25) y publica "El Modernismo» en el Nuevo Mercurio de París de mayo 1907 (26). Confiesa detestar y no entender a Góngora, y no creer que valga la pena gastar esfuerzo en descifrarlo; llama a los modernistas extravagantes, blandengues $y$ falsos, $y$ añade:

No habrá redención para nuestras letras mientas el literato no sienta todo lo que de sacerdocio debe haber en su función social, y se proponga sobre todo $y$ ante todo agradar al público.

La última frase merece ser retenida, porque nos ayudará a entender el sentido específico y no habitual que en Unamuno tiene el concepto de «popularidad»; porque para él, como veremos, un autor popular puede no gustar al pueblo.

En "Culto al porvenir» (La Nación, B. Aires, 1914) (27) se burla Unamuno de la estética de Marinetti, que reduce a un efectismo llamado a

(23) Ibid., III, pp. 51-59.

(24) Ibid., IV, pp. 1135-1136.

(25) lbid., III, pp. 962-964.

(26) Ibid., VII, pp. 1303-1304.

(27) Ibid., IV, pp. 1096-1101. 
deslumbrar y escandalizar a los incautos, aunque reconozca en algunas formulaciones futuristas un buen deseo, aunque equivocado en su concreción, de regeneracionismo.

En Cómo se hace una novela y en la contestación a la encuesta del extraordinario dedicado a Góngora por La Gaceta Literaria, en junio de 1927, î́nsistírá en sus desdenes y censuras hacia las pretensiones de la generación de 1927. Y en el prólogo a El hermano Juan (1934) (28) ridiculizará los principios freudianos y marxistas a la par, con lo cual estaba evidentemente desestimando el movimiento superrealista.

$3^{\circ}$. CONCEPTO UNAMUNIANO DE ESCRITOR POPULAR. Para enfocarlo hemos de partir de la distinción unamuniana entre pueblo y público. La confusión entre ambos provoca, opina $\mathrm{D}$. Miguel, las tradicionales y erróneas interpretaciones de la justificación del escritor sobre la base de su aceptación en el mercado del libro o de su éxito de taquilla. El pueblo, en opinión de Unamuno, es genéricamente toda la masa social, y específicamente aquéllos que están necesitados de educación y orientación. No se trata de una educación que consistiera sólo en difundir la letra muerta de los conocimientos científicos, sino de una educación superior, que confiere al hombre conciencia de su naturaleza y fines. Al abandonar su ideario marxista perderá Unamuno la convicción de que la educación pretendida consista en difundir entre el proletariado los principios necesarios desde una óptica de clase; con el concepto de «pueblo» dispone de un instrumento ecléctico y equívoco, en el que se halla el punto más débil de su razonamiento; renunciando a los planteamientos materialistas cae en un confuso regeneracionismo espiritualista que es, con todo, el ingrediente más personal de su doctrina.

El público es el consumidor de arte, y para Unamuno, tan dado a la artificiosidad, o a cualquier forma de error artístico, como los malos escritores. Hay un público elitista, desconectado de los problemas verdaderamente humanos, que se guía ante todo por el snobismo y el culto a la novedad, y es el responsable de la existencia de las tendencias artísticas artificiosas. Pero nadie llamaría populares a esas tendencias porque, aunque tengan público, lo tienen muy reducido. El público más peligroso es el público amplio, que no busca en el arte más que el halago facilón de sus instintos más elementales. Por su importancia cuantitativa, ese público puede dar la impresión de ser el pueblo, y desnortar el concepto de literatura popular. Para Unamuno, la falsa literatura po-

(28) Ibid., V, pp. 713-725. 
pular de su tiempo se distinguía por la omnipresencia del tema erótico, y son muy reveladores a este respecto sus artículos «Sobre la lujuria» (29) Y «Sobre la pornografía» (30), los dos en La Nación 1907. Se escandaliza D. Miguel de la «lujuria pública» que causan en los cafetines y teatros de Madrid las cupletistas que se exhiben medio desnudas con gestos y meneos sicalípticos, y afirma chuscamente que la lujuria es mejor aliada de la tiranía que la bebida, porque «en la lucha social los pueblos relativamente más castos y más borrachos llevan ventaja a los relativamente menos bebedores y más lujuriosos". También propone, para que ande bien España, que los iiberales dejen a sus queridas; y para que no le tachen de moralista cateto, asegura D. Miguel haber estado, como el que más, en París, y haber visto allí coristas en cueros vivos.

Dejemos a los doctores del marxismo la ponderación de tan graves cuestiones, y tornemos al hilo de la argumentación. Lo que tiene amplia audiencia de público no es para Unamuno lo verdadero y necesariamente popular. Su concepto de literatura popular podemos encontrarlo en su conferencia en el Ateneo de Sevilla 1896 «Sobre el cultivo de la demótica» (31), y en los artículos "Los cerebrales» (La llustración Española y Americana 1899) (32) y "A propósito de Josué Carducci» (La Nación, 1907) (33), entre otros.

Para Unamuno, la popularidad no significa abdicación de la personalidad del escritor. Todo escritor, para serlo, ha de poseer un cierto grado de cultura, que lo diferencia ipso facto del pueblo analfabeto, y le confiere individualidad. Pero esa individualidad no debe convertirse nunca en individualismo. El verdadero escritor, o escritor popular, es un individuo culto que no por ello se siente desarraigado del pueblo, sino que comulga con la forma de ser y de sentir de éste, y sabe expresar ese ser con idoneidad artística. Su diferencia y superioridad con respecto al pueblo no reside, como quieren para sí los artificiosos, en poseer una mentalidad radicalmente superior por lo distinta, sino tan sólo, y teniendo la misma mentalidad del pueblo, en ser consciente de ella' (o sea, capaz de racionalizarla más allá de los meros instintos) y capaz de infundirla en obras de arte. Tendrá entonces ese escritor, dice Unamuno, "individualidad social», y su obra será "alma del pueblo individualiza-

(29) Ibid., III, pp. 316-320.

(30) Ibid., III, pp. 321-325.

(31) Ibid., IX, pp. 47-59.

(32) Ibid., VII, pp. 412-415.

(33) lbid., III, pp. 595-600. 
da». Es lo que en su opinión caracterizó la Epica medieval y el Romancero. Definición de poeta popular que coincide con la teoría Neotradicionalista de Menéndez Pidal.

Ante la obra del escritor popular, el pueblo adquiere conciencia de su propio ser y pensar, que desconocia hasta que le fue así revelado. Y el pueblo se desorienta y queda flotando en la pasividad y la ignorancia cuando los cultos se niegan a ser escritores populares. Esa ẻs, por lo tanto, la misión social del escritor, qúe no inscribirse en un partido; y tiene una dimensión didáctica, desde luego, pero de carácter ético y cognoscitivo, más allá del servicio a fines políticos coyunturales, utilitarios o partidistas.

La justificación doctrinal del concepto de escritor como «pastor del pueblo", que se sumerge en el seno del ser de su rebaño para.darle así conciencia de ser y conducirlo, está formulada en En torno al casticismo:

La tradición eterna es lo que deben buscar los videntes de todo pueblo, para elevarse a la luz, haciendo consciente en ellos to que en el pueblo es inconsciente, para guiarle asi mejor [...] El hombre, esto es lo que hemos de buscar en nuestra alma. $Y$ hay, sin embargo, un verdadero furor por buscar en si lo menos humano; llega la ceguera a tal punto, que llamamos original a lo menos original. Porque lo original no es la mueca, ni el gesto, ni la distincion, ni lo original; lo verdaderamente original es lo originario, la humanidad en nosotros. | Gran locura la de querer despojarnos del fondo común a todos, de la masa idéntica sobre que se moldean las formas diferenciales, de lo que nos asemeja y une, de lo que hace que seamos projimos, de la madre del amor, de la humanidad, en fin, del hombre, del verdadero hombre, del legado de la especie! (34).

El escritor popular no puede ser, ya que público y pueblo no son to mismo, aquél que tiene éxito inmediato y multitudinario en una sociedad dominada por la subliteratura mercantilizada que encuentra terreno abonado por la ignorancia; sino el que crea conciencia del ser popular, aunque no tenga éxito y aunque el pueblo, en un primer momento, no lo lea. En este sentido conviene recordar dos artículos de

(34) Ibid., I, pp. 794795. 
Unamuno: «Los escritores y el pueblo» (La Nación, 1908) (35) y «Poesía y política» (La Voz de Guipúzcoa, 1934) (36). En el primero leemos que "la multitud no sabe cuáles son sus angustias ni sus anhelos», y que «se puede y se debe pelear por el pueblo, por su bien, yendo contra el pueblo mismo, aun a riesgo de pasarse lo mejor de la vida solo y aislado". Ello porque el pueblo, que no sabe, se contamina de público, y se vuelve, dice Unamuno, «plebe» y "vulgo». La misión del escritor no es mezclarse con la plebe, sino convertirla en pueblo, luchando contra los gustos del pueblo desnaturalizado, cosa que es pueblo le agradecerá, aunque sea a la larga. En el segundo artículo, haciendo balance de su vida, afirma Unamuno que esa tarea ha sido su mejor participación en la vida política del país. $Y$ dice no entender a los que le recomiendan que se deje de política y haga literatura, porque ambas cosas le parecen lo mismo. En su prólogo a Querellas del ciego de Robliza de Luis Maldonado (1894) (37), decía Unamuno:

Muchos, muchísimos cantos populares, hondamente populares, los más populares acaso, proceden de hombres doctos y cultos que se han sorbido y asimilado el alma de la muchedumbre, que templaron los latidos de su corazón al compás de los latidos del gran corazón del pueblo, del espíritu colectivo.

Y en «Sobre el cultivo de la demótica»:

[El genio poético] es el individuo más pueblo, el que mejor resume el espíritu de las muchedumbres, el que hace en si pensamiento individual y concreto los vagos anhelos sociales, [...] el pueblo hecho hombre para encarnar sus imaginaciones poéticas.

Para que un escritor sea popular, opina Unamuno, ha de adoptar una actitud diametralmente opuesta a la artificiosidad: de ella nos habla en "Orfebrería literaria» (Los Lunes de El Imparcial, 1913) (38) y "El dolor de pensar» (La Esfera, 1915) (39). El auténtico escritor no se preocupará, naturalmente, por la originalidad o la belleza formal; sólo escribirá cuando un impulso genuino lo lleve a expresarse; lo hará con apasionamien-

(35) Ibid., III, pp. 294-298.

(36) Ibid., VII, pp. 818-819.

(37) Ibid., VIII, pp. 883-889.

(38) Ibid., VII, pp. 846-849.

(39) Ibid., VIII, pp. 347-350. 
to, esencialidad y desnudez, y su obra se caracterizará por la humanidad y la trascendencia ética colectiva. Dice el artículo de La Esfera:

Yo, señor mío, escribo con la sangre de mi corazón, no con tinta neutra, mis pensamientos, muchas veces contradictorios, mis dudas, mis anhelos, mis sedes y hambres del espíritu [...] y sé que todo pensamiento escrito con sangre del corazón es una cosa de belleza, digan lo que quieran los artistas de la forma [...].

Yo, señor mío, quiero encarnar pensamientos y no vestirlos. Cuanto más desnudos me salgan, mejor.

Lo cual equivale a legitimar el derecho a escribir mal, en nombre de la verdad y la autenticidad, de lo cual dio cumplida razón Unamuno en su obra poética.

Resulta, en resumen, que Unamuno propugna una suerte de compromiso del escritor que consiste en una atención auténtica, sincera y desprovista de artificio a las grandes cuestiones existenciales propias del vivir humano. Su obra poética es una excelente ilustración de tal punto de vista. El volumen de 1907, titulado Poeslas, lleva dos poemas con valor de manifiesto, "Credo poético» y "Denso, denso» (40):

Piensa el sentimiento, siente el pensamiento; que tus cantos tengan nidos en la tierra y que cuando en vuelo a los cielos suban tras las nubes no se pierdan.

No te cuides en exceso del ropaje, de escultor y no de sastre es tu tarea, no te olvides de que nunca más hermosa que desnuda está la idea.

Mira, amigo, cuando libres al mundo tu pensamiento, cuida ante todo que sea denso, denso.

(40) Ibid., VI, pp. 168-170. 


\section{$Y$ cuando sueltes la espita que cierra tu sentimiento, que en tus cantos éste mane denso, denso.}

En estas Poesías de 1907 encontramos todo un repertorio de temas «humanos»: los de la vida cotidiana, diaria, conyugal y familiar (por ejemplo, las secciones tituladas «Incidentes domésticos" y "Cosas de niñosı); los existenciaies (problemas, angustias y reflexiones filosóficas derivados de la condición humana: paso del tiempo, muerte, inmortalidad) en poemas como "El buitre de Prometeo», "Sísifo» o "Elegía en la muerte de un perro»; los religiosos, serenos y conflictivos («El Cristo de Cabrera», o la sección "Salmos»); y el canto a las tierras y lugares de España, con esa atención noventayochista al paisaje que parece simbolizar tanto el estado anímico del poeta como, en ocasiones, el destino del pueblo español ("Tú me levantas, tierra de Castilla», "El mar de encinas», "Salamanca», "Las montañas de mi tierra»). Sin que falten poemas cívico-políticos, en forma de reflexiones interiorizadas ( $\mathrm{A}$ la libertad», "Al pie del sauce»).

El Rosario de sonetos líricos (1911) prolonga las líneas maestras del libro anterior, y con El Cristo de Velázquez (1920) estamos ante el gran tema predilecto de Unamuno, el religioso, en forma de manifestaciones de misticismo, evocación de episodios de la vida, Pasión y muerte de Jesús y algunos aditamentos de teología cristológica. Tras Rimas de dentro (1923) llegamos, en 1924, a Teresa, libro de recreación del espíritu romántico y homenaje a Bécquer, con el que Unamuno se anticipa a la polémica que años después iba a estallar en torno a la "pureza» o «impureza» del arte, y a la revalorización de Bécquer y Garcilaso como poetas «humanos».

De Fuerteventura a París (1925) continúa los temas religiosos y existenciales, y añade los derivados del encontronazo de Unamuno con la Dictadura: tenemos sátiras contra Alfonso XIII y Primo de Rivera; la concreción, ante la circunstancia política del momento, del tema de la preocupación por España, y lo mismo el de la relación del hombre con un Dios opresor, vista ahora como castigo político de España. También el tema del exilio.

Unamuno se daba cuenta de que algunas de las novedades temáticas del libro de 1925 iban en cierto modo en contra de sus propias ideas acerca de lo que debe y no debe ser el arte comprometido; en el prólogo 
de su Romancero de/ destierro se siente obligado a defender la coherencia de su poesía política y sus ideas teóricas, diciendo que la primera, en su caso, no es poesía de circunstancias, ya que en él lo coyuntural está sentido "en eternidad», cosa que hemos de aceptar como propia de quien se sentía autorizado a cambiar de opinión cuando se lo pedía el cuerpo, y dijo que, si bien tenía ideas, las ideas no lo tenían a él (41).

El Cancionero, publicado póstumamente, no añade más que variaciones sobre los temas enunciados; podría destacarse el «Fragmento de un Arte Poética...川, con sus invocaciones a la poesia impura o humana, insultos a Góngora y a los «torremarfileños poetisos», y referencia a la densidad expresiva de que hablaba ya su primer libro de versos.

No sé si estas reflexiones serán algo más que un retrato parcial de «mi» Unamuno. He intentado recoger y ordenar un pensamiento disperso en rompecabezas a lo largo de cuarenta años de su actividad literaria, sin disfrazar la ambigüedad que hay en él. Quizás fue esa ambigüedad lo que lo hizo tan presente entre los escritores de su tiempo, y la que acaso pueda seguir interesando siempre, como actitud al menos, si no en sus soluciones y contenidos; porque es una ambigüedad de buena ley.

(41) En la respuesta a Cassou al frente de Cómo se hace una novela, ed. cit., VIII, 722. 